\title{
Long-term outcomes after surgical treatment of pediatric neurogenic thoracic outlet syndrome
}

\author{
Jennifer Hong, MD,, Jared M. Pisapia, MD, ${ }^{2}$ Zarina S. Ali, MD, ${ }^{2}$ Austin J. Heuer, ${ }^{3}$ \\ Erin Alexander, BS, ${ }^{3}$ Gregory G. Heuer, MD, PhD, ${ }^{2,3}$ and Eric L. Zager, MD ${ }^{2}$
}

1'Divison of Neurosurgery, Dartmouth-Hitchcock Medical Center, Lebanon, New Hampshire; '2Department of Neurosurgery, University of Pennsylvania, Philadelphia; and 'Division of Neurosurgery, The Children's Hospital of Philadelphia, Pennsylvania

\begin{abstract}
OBJECTIVE Neurogenic thoracic outlet syndrome (nTOS) is an uncommon compression syndrome of the brachial plexus that presents with pain, sensory changes, and motor weakness in the affected limb. The authors reviewed the clinical presentations and outcomes in their series of pediatric patients with surgically treated nTOS over a 6 -year period.
\end{abstract}

METHODS Cases of nTOS in patients age 18 years or younger were extracted for analysis from a prospective database of peripheral nerve operations. Baseline patient characteristics, imaging and neurophysiological data, operative findings, and outcomes and complications were assessed.

RESULTS Twelve patients with 14 cases of nTOS surgically treated between April 2010 and December 2016 were identified. One-third of the patients were male, and 2 male patients underwent staged, bilateral procedures. Disabling pain (both local and radiating) was the most common presenting symptom (100\%), followed by numbness (35.7\%), then tingling $(28.6 \%)$. The mean duration of symptoms prior to surgery was $15.8 \pm 6.6$ months (mean \pm SD). Sports-related onset of symptoms was seen in $78.6 \%$ of cases. Imaging revealed cervical ribs in 4 cases, prominent C-7 transverse processes in 4 cases, abnormal first thoracic ribs in 2 cases, and absence of bony anomalies in 4 cases. Neurophysiological testing results were normal in $85.7 \%$ of cases. Conservative management failed in all patients, with 5 patients reporting minimal improvement in symptoms with physical therapy. With a mean follow-up after surgery of $22 \pm 18.3$ months (mean \pm SD), pain relief was excellent (> 90\%) in 8 cases $(57.1 \%)$, and good (improved $>50 \%$ ) in 6 cases $(42.9 \%)$. On univariate analysis, patients who reported excellent pain resolution following surgery at long-term follow-up were found to be significantly younger, and to have suffered a shorter duration of preoperative symptoms than patients who had worse outcomes. Lack of significant trauma or previous surgery to the affected arm was also associated with excellent outcomes. There were 4 minor complications in 3 patients within 30 days of surgery: 1 patient developed a small pneumothorax that resolved spontaneously; 1 patient suffered a transient increase in pain requiring consultation, followed by hiccups for a period of 3 hours that resolved spontaneously; and 1 patient fell at home, with transient increased pain in the surgically treated extremity. There were no new neurological deficits, wound infections, deep vein thromboses, or readmissions.

CONCLUSION Pediatric nTOS commonly presents with disabling pain and is more frequently associated with bony anomalies compared with adult nTOS. In carefully selected patients, surgical decompression of the brachial plexus results in excellent pain relief, which is more likely to be seen in younger patients who present for early surgical evaluation. https://thejns.org/doi/abs/10.3171/2017.7.PEDS17257

KEY WORDS thoracic outlet syndrome; brachial plexus; pediatric; anterior scalenectomy; peripheral nerve; pain

$\mathrm{T}$ Horacic outlet syndrome (TOS) is a neurovascular compression syndrome caused by constriction of the brachial plexus or subclavian artery and vein as they exit the thoracic outlet. This syndrome can have a variable presentation, and symptoms are typically divided into vascular or neurogenic, although an individual may have a mixture of both. Neurogenic TOS (nTOS) has a wide constellation of symptoms including pain, paresthesias, and motor deficits in the neck and/or extremity. ${ }^{26}$ The diagnosis of TOS is controversial, because the definition describes the location of the compression but not a specific pathogenesis.

In adults, the incidence of TOS is reported to be $0.3 \%-$ $2 \%$ of the general population between the ages of 25 and

ABBREVIATIONS EMG = electromyography; NCS = nerve conduction studies; $\mathrm{nTOS}=$ neurogenic thoracic outlet syndrome; $\mathrm{POD}=$ postoperative day; $\mathrm{TP}=$ transverse process; UEFI = upper-extremity functional index; US = ultrasound.

SUBMITTED May 15, 2017. ACCEPTED July 21, 2017.

INCLUDE WHEN CITING Published online November 10, 2017; DOI: 10.3171/2017.7.PEDS17257. 
40 years, with $>80 \%$ of patients falling between those ages. ${ }^{18}$ Women are 3 times more likely to be affected than men. Thoracic outlet syndrome also affects children, and appears to be much rarer in this age group, although the true incidence is unknown. Pediatric or early-onset TOS is poorly understood; the literature to date consists of small case series with limited follow-up. , $11,13,14,16,21-23,26-30$ There may be several reasons for this paucity, including a lack of familiarity with TOS among pediatricians, minimization of symptoms by children, or difficulty communicating symptoms to adults in young children. Nevertheless, TOS in children and young adults remains understudied.

Management of pediatric TOS is therefore challenging, with no clear guidelines for selecting patients for intervention. Unlike adult TOS, which is overwhelmingly neurogenic $(95 \%)$ in nature, ${ }^{8,19}$ pediatric TOS is often vascular, with only one-third of patients presenting with neurogenic symptoms. ${ }^{29}$ Compared with adult nTOS, pediatric nTOS is less prevalent, more difficult to diagnose, and more likely to have a distinct pathogenesis and natural history. Whether the same treatment strategies used in adult TOS are effective in children is debatable, particularly in young children who are still developing. Data on outcomes after treatment of TOS in children are therefore important to analyze, especially in patients with long-term follow-up.

We undertook a retrospective review of children presenting to 2 institutions. Particular attention was paid to the role of conservative treatment, intraoperative findings, and clinical follow-up.

\section{Methods}

\section{Participants and Study Design}

Following approval by the institutional review boards of the University of Pennsylvania and Children's Hospital of Philadelphia, hospital records and a prospectively maintained database of all peripheral nerve operations at these 2 institutions were queried for TOS and ICD-9 codes 21700 and 64713 between April 2010 and July 2016. A diagnosis of TOS was made based on hospital discharge documentation and referral information.

\section{Clinical Variables and Outcomes Assessment}

Clinical data were retrieved through retrospective chart review. Data available included age, sex, presenting symptoms, clinical examination results, imaging findings, electrophysiology studies, operative findings, and clinical follow-up.

\section{Work-Up and Management}

Children referred to the Hospital of the University of Pennsylvania or Children's Hospital of Philadelphia for evaluation of possible TOS underwent a complete history and a detailed physical and neurological examination. Plain chest or cervical spine radiographs were obtained in all patients to rule out a cervical rib (Fig. 1). Electromyography (EMG) and nerve conduction studies (NCS) were obtained in all patients. All patients except for 2 who underwent MRI of the cervical spine or affected brachial plexus. A chest CT was obtained in 2 patients to better evaluate bony anomalies. Ultrasound (US) of the affected

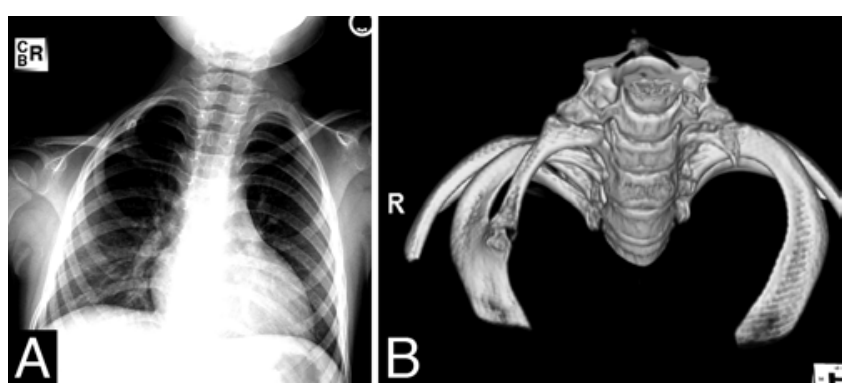

FIG. 1. Plain chest radiograph (A) and reconstructed chest CT (B) demonstrating a right cervical rib, with fusion to the first thoracic rib and resulting pseudarthrosis in a 12-year-old girl with right nTOS.

brachial plexus with dynamic maneuvers with or without US-guided steroid injection of the brachial plexus was obtained when available and if the patient and parents were amenable. If vascular symptoms were present, US of the vessels of the thoracic outlet was obtained. All patients underwent a trial of physical therapy for at least 4 weeks (many for 6 months) prior to surgical intervention.

\section{Surgical Approach and Follow-Up}

All patients underwent an anterior supraclavicular brachial plexus exploration, with anterior scalenectomy and, when present, resection of cervical rib or other bony sites of compression (Fig. 2). Neuromonitoring with a handheld stimulator as well as traditional console-based monitoring (compound muscle action potentials and somatosensory evoked potentials) was used in all cases. The patients were treated as previously described. ${ }^{9}$

All patients were discharged home once discharge criteria were met, typically on postoperative day (POD) 1 . All patients returned to clinic for routine follow-up at 4-6 weeks, or as travel schedules allowed. No routine repeat imaging was obtained.

Long-term telephone follow-up was attempted for all patients. A standardized questionnaire asking patients to rate their pain relief, residual numbness or tingling, motor weakness, and satisfaction with the operation was administered. The upper-extremity functional index (UEFI) $)^{7,24}$ was also administered to all patients, and they were asked whether they would recommend surgery to other patients with nTOS. Three attempts were made on separate dates to contact patients. When the patient was not available to answer questions, follow-up data were obtained from a parent.

\section{Statistical Analysis}

Statistical analysis was conducted with commercially available R software (www.r-project.org). Contingency tables were created and chi-square values were calculated. The mean is expressed $\pm \mathrm{SD}$ throughout.

Univariate analyses were performed with the Student t-test (2-tailed) for numeric variables and with the Fisher exact test (2-tailed) for categorical variables to determine significant associations between these variables and an excellent outcome, defined as $>90 \%$ relief of painful symptoms following surgery. A p value of $\leq 0.05$ was consid- 


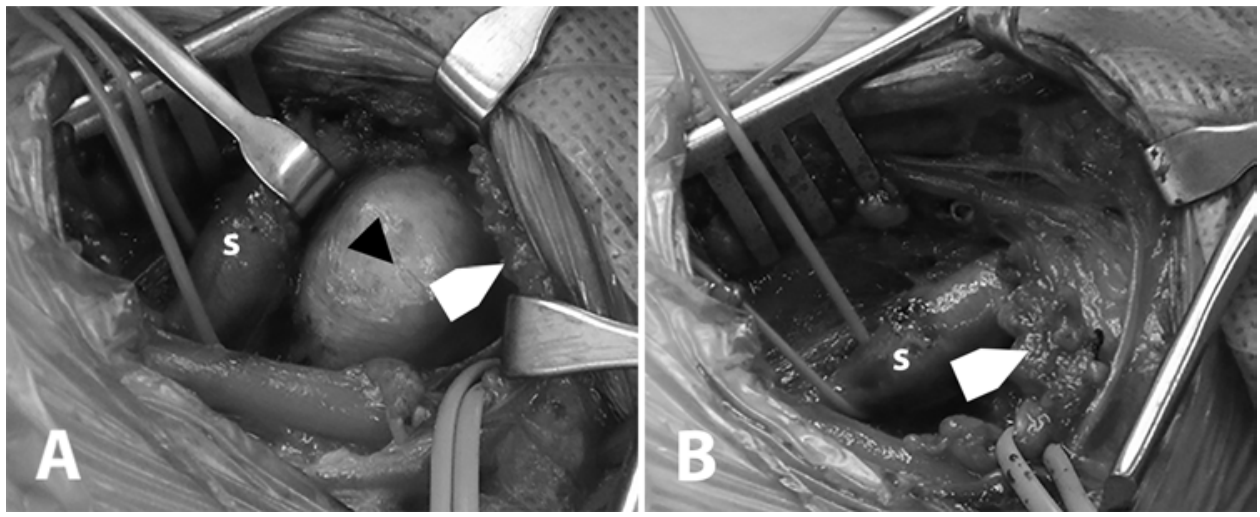

FIG. 2. Intraoperative views of supraclavicular brachial plexus exploration, anterior scalenectomy, and resection of the cervical rib and pseudarthrosis in the same patient. A: The black arrowhead indicates the pseudarthrosis at the junction of the cervical rib and first rib. The white arrow indicates the cut edge of the anterior scalene. The subclavian artery is displaced superiorly by the cervical rib. The bottom vessel loop is placed around the lower trunk of the brachial plexus, which is displaced inferiorly. B: Photograph obtained after resection of the cervical rib and associated pseudarthrosis. The white arrow indicates the cut edge of the anterior scalene. The subclavian artery has returned to its normal course. Bottom vessel loop is placed around the lower trunk of the brachial plexus, which has also returned to its normal course. $S=$ subclavian artery.

ered statistically significant. Multivariate analysis was not pursued due to the small size of the population.

\section{Results}

\section{Population Demographics and Presentation}

Fourteen cases of nTOS were reviewed in 12 children (Table 1). The mean age at time of surgery was $15.2 \pm 2.8$ years, with an age range from 8 to 18 years. One-third of the patients were male, with 2 male patients undergoing staged, bilateral procedures (Cases 1 and 3).

Presenting symptoms were primarily pain (in all patients) of the neck, shoulder, arm, and hand. Patients also presented with numbness (35.7\% of cases), and tingling ( $28.6 \%$ of cases). Three patients (21.4\% of cases) had concurrent vascular symptoms including mottling or swelling of the arm and hand. Half of all cases involved the dominant hand, with 2 patients suffering bilateral presentations that were separated by time periods of 9 months in one, and 4 years in the other. The mean duration of symptoms prior to treatment was $15.8 \pm 6.6$ months.

A history of significant participation in sports, in which playing sports was associated with exacerbation or onset of nTOS symptoms, was seen in $78.6 \%$ of cases-with $71.4 \%$ of cases occurring in sports that involve the upper extremity (i.e., swimming, baseball, crew, water polo). Trauma was associated with $28.6 \%$ of cases and included motor vehicle accident, sports injury, and previous surgery.

On examination, $71.4 \%$ of the cases of pediatric nTOS exhibited a positive Roos maneuver and $64.3 \%$ demonstrated a positive Tinel's sign. Patients reported tenderness to palpation over the brachial plexus in $57.1 \%$ of cases and numbness in the hand in $28.6 \%$ of cases. Twelve cases $(85.7 \%)$ had at least one positive examination finding. Although some patients complained of subjective weakness, all patients were at full strength to confrontation and demonstrated normal reflexes on examination.

\section{Imaging Findings and Electrophysiology}

All patients underwent chest or cervical spine radiographs to evaluate for the presence of cervical ribs or prominent transverse processes (TPs). In our 14 cases, we observed 4 cervical ribs (28.6\%), 4 prominent TPs of the lower cervical vertebra (28.6\%), and 2 first rib anomalies, namely a fused first and second rib and a partially resected first rib (14.3\%). Four cases did not have any bony anomalies. Additional imaging included MRI of the cervical spine in 8 patients, which demonstrated a congenital fusion of C-2 and C-3 in 1 patient, and a mild C5-6 disc bulge in another; MRI of the brachial plexus was performed in 6 patients, demonstrating an intramuscular course of the brachial plexus in 1 patient (through the anterior scalene muscle) and postoperative changes from previous transaxillary rib resection in another patient. The CT scans of the chest in 2 patients demonstrated bilateral cervical ribs in one patient and a synchondrosis of the ipsilateral first and second ribs in another.

Overall, the yield of MRI of the cervical spine and brachial plexus for abnormalities was $25 \%$, although it is unclear how much these abnormalities contributed to patient symptomatology. Ultrasound of the brachial plexus with dynamic maneuvers and possible steroid injection of the plexus was obtained in 9 cases $(64.3 \%)$. This demonstrated 2 cases with dynamic neural compression (i.e., when the arm was elevated), 2 cases of dynamic arterial compression, and 1 diagnosis of bilateral vascular TOS by wrist indices. Ultrasound was the most sensitive imaging study for compression, with positive findings of concern for compression in 50\% of patients. Of 4 patients who underwent US-guided steroid injections, 3 (75\%) reported transient reduction in pain, and 1 noticed no changes.

All patients underwent EMG (Table 2) and NCS. Two studies $(14.2 \%)$ were abnormal, with one study demonstrating a mild plexopathy of the lower trunk, and another with mild bilateral C-5 radiculopathy. 


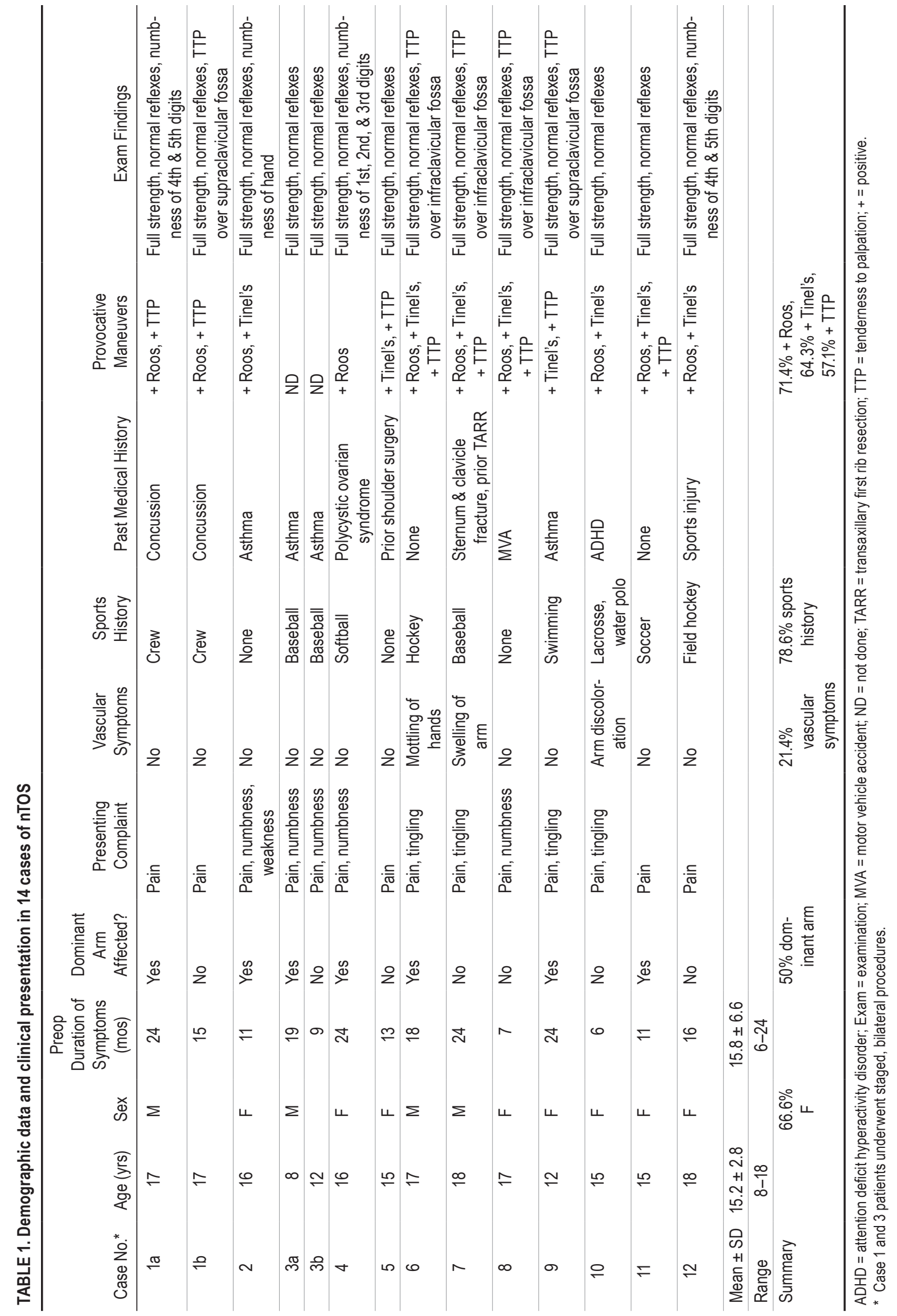


TABLE 2. Imaging and electrophysiology in pediatric nTOS

\begin{tabular}{|c|c|c|c|c|c|c|c|}
\hline $\begin{array}{l}\text { Case } \\
\text { No. }{ }^{*}\end{array}$ & $\begin{array}{l}\text { MRI of } \\
\text { Cervical } \\
\text { Spine }\end{array}$ & $\begin{array}{l}\text { MRI of Brachial } \\
\text { Plexus }\end{array}$ & CT of Chest & Radiography & US & EMG & $\begin{array}{l}\text { Bony } \\
\text { Anomalies on } \\
\text { Affected Side }\end{array}$ \\
\hline $1 a$ & None & $\begin{array}{l}\text { Normal, prominent } \\
\text { musculature }\end{array}$ & None & $\begin{array}{l}\text { Bilat prominent } \\
\text { C-7 TP }\end{array}$ & Normal & Normal & $\begin{array}{c}\text { Elongated } \\
\text { C-7 TP }\end{array}$ \\
\hline $1 b$ & None & $\begin{array}{l}\text { Normal, prominent } \\
\text { musculature }\end{array}$ & None & NP & Normal & Normal & $\begin{array}{c}\text { Elongated } \\
\text { C-7 TP }\end{array}$ \\
\hline 2 & $\begin{array}{l}\text { Bilat cervical } \\
\text { ribs at C-7 } \\
\text { \& C-6, w/ } \\
\text { fusion of } \\
\text { multiple } \\
\text { ribs on rt }\end{array}$ & None & None & $\begin{array}{l}\text { Right C-6 riblet } \\
\text { \& partial C-7 } \\
\text { rib, complete It } \\
\text { C-7 rib, partial } \\
\text { fusion of rt T-1 \& } \\
\text { T-2 ribs }\end{array}$ & $\begin{array}{l}\text { Apposition of the brachial } \\
\text { plexus \& the cervical rib } \\
\text { on the rt, w/ dynamic } \\
\text { movement }\end{array}$ & $\begin{array}{l}\text { Mild } \\
\text { plexopathy } \\
\text { of It lower } \\
\text { trunk }\end{array}$ & Cervical rib \\
\hline $3 a$ & Normal & Normal & None & $\begin{array}{l}\text { Bilat cervical ribs, } \\
r t>\text { lt }\end{array}$ & None & Normal & Cervical rib \\
\hline $3 b$ & NP & Normal & None & NP & None & Normal & Cervical rib \\
\hline 4 & Normal & None & None & $\begin{array}{l}\text { Bilat slight enlarge- } \\
\text { ment of C-7 TP }\end{array}$ & Normal & Normal & $\begin{array}{c}\text { Elongated } \\
\text { C-7 TP }\end{array}$ \\
\hline 5 & None & None & None & Normal & Normal & Normal & None \\
\hline 6 & $\begin{array}{l}\text { Congenital } \\
\text { fusion of } \\
\text { C2-3 }\end{array}$ & $\begin{array}{l}\text { Intramuscular course } \\
\text { of C-5 \& C-6, bilat } \\
\text { enlargement of } \\
\text { subclavius muscles }\end{array}$ & None & C2-3 fusion & $\begin{array}{l}\text { Bilat compression of the } \\
\text { brachial plexus w/ } \\
\text { dynamic movement }\end{array}$ & $\begin{array}{l}\text { Bilat mild C-5 } \\
\text { radicu- } \\
\text { lopathy }\end{array}$ & None \\
\hline 7 & None & $\begin{array}{l}\text { Expected postop } \\
\text { changes, elon- } \\
\text { gated C-7 TP, It > } \\
\text { rt, not contacting } \\
\text { the middle trunk, } \\
\text { normal plexus }\end{array}$ & None & $\begin{array}{l}\text { Status postresec- } \\
\quad \text { tion for It } 1 \text { st rib }\end{array}$ & Normal & Normal & $\begin{array}{l}\text { Remnant of It } \\
1 \text { st rib }\end{array}$ \\
\hline 8 & Normal & None & $\begin{array}{l}\text { Synchondrosis of It } \\
\text { 1st \& 2nd rib }\end{array}$ & Normal & $\begin{array}{l}\text { Wrist indices demonstrate } \\
\text { bilat TOS }\end{array}$ & Normal & $\begin{array}{l}\text { Synchondro- } \\
\text { sis of It 1st } \\
\text { \& 2nd ribs }\end{array}$ \\
\hline 9 & None & None & $\begin{array}{l}\text { Bilat cervical ribs, rt } \\
\text { much larger than } \\
\text { It; rt rib forming } \\
\text { pseudarthrosis, } \\
\text { w/ thickened, } \\
\text { expanded T-1 rib }\end{array}$ & $\begin{array}{l}\text { Bilat cervical ribs, } \\
\text { rt }>\text { It }\end{array}$ & None & Normal & $\begin{array}{l}\text { Cervical rib } \\
\text { w/ pseud- } \\
\text { arthrosis }\end{array}$ \\
\hline 10 & Normal & Normal & None & Normal & $\begin{array}{l}\text { Compression of subclavian } \\
\text { artery \& vein w/ dynamic } \\
\text { movement }\end{array}$ & Normal & None \\
\hline 11 & Normal & None & None & Normal & None & Normal & None \\
\hline 12 & $\begin{array}{l}\text { Mild C5-6 } \\
\text { disc bulge }\end{array}$ & Normal & None & $\begin{array}{l}\text { Lt C-7 TP slightly } \\
\text { enlarged }\end{array}$ & $\begin{array}{l}\text { Mild enlargement of roots, } \\
\text { trunks, \& divisions of It } \\
\text { brachial plexus, subclavi- } \\
\text { an artery btwn middle \& } \\
\text { lower trunk, compression } \\
\text { of vascular structures w/ } \\
\text { dynamic movement }\end{array}$ & Normal & $\begin{array}{l}\text { Prominent It } \\
\text { C-7 TP }\end{array}$ \\
\hline
\end{tabular}

$\mathrm{NP}=$ not performed.

* Case 1 and 3 patients underwent staged, bilateral procedures.

\section{Neurosurgical Interventions and Outcomes}

All patients underwent anterior supraclavicular brachial plexus exploration and anterior scalenectomy (Table 3). Furthermore, additional compressive soft tissue and bony structures were removed if they were noted to be abutting nerves at the time of surgery. This included resection of a rib or prominent TP in 5 cases (35.7\%), division of Sibson's fascia (suprapleural membrane) in 3 cases (21.4\%), and a 
TABLE 3. Outcomes following surgical intervention for pediatric nTOS

\begin{tabular}{|c|c|c|c|c|c|c|c|c|}
\hline Case No.* & $\begin{array}{l}\text { Duration of } \\
\text { FU (mos) }\end{array}$ & Intraop Findings & $\begin{array}{l}\text { LOS } \\
\text { (days) }\end{array}$ & $\begin{array}{l}\text { Pain Relief } \\
(\%)\end{array}$ & $\begin{array}{l}\text { Numbness, } \\
\text { Tingling }\end{array}$ & UEFI Score & $\begin{array}{l}\text { Surgery } \\
\text { Rec }\end{array}$ & $\begin{array}{l}\text { 30-Day } \\
\text { Complications }\end{array}$ \\
\hline $1 a$ & 12.5 & $\begin{array}{l}\text { Fibrous bands in the anterior } \\
\text { scalene }\end{array}$ & 2 & 70 & $\begin{array}{l}\text { Occasional, } \\
\text { improved }\end{array}$ & 73 & Yes & $\begin{array}{l}\text { Transiently } \\
\text { increased pain } \\
\text { immediately } \\
\text { postop requiring } \\
\text { pain consult, } \\
\text { hiccups for } 3 \mathrm{hrs} \\
\text { that resolved } \\
\text { spontaneously } \\
\text { on POD } 3\end{array}$ \\
\hline $1 b$ & 26 & $\begin{array}{l}\text { Fibrous bands in the anterior } \\
\text { scalene }\end{array}$ & 1 & 85 & $\begin{array}{l}\text { Occasional, } \\
\text { improved }\end{array}$ & 73 & Yes & None \\
\hline 2 & 21 & $\begin{array}{l}\text { Hypertrophic anterior scalene } \\
\text { muscle w/ fibrous firm bands }\end{array}$ & 1 & 99 & $\begin{array}{l}\text { Occasional, } \\
\text { w/ heavy } \\
\text { activity }\end{array}$ & 77 & Yes & None \\
\hline $3 a$ & 59 & $\begin{array}{l}\text { Fibrous bands in the anterior sca- } \\
\text { lene muscle, cervical rib }\end{array}$ & 1 & 100 & None & 79 & Yes & None \\
\hline $3 b$ & 21 & $\begin{array}{l}\text { Hypertrophic anterior scalene } \\
\text { muscle, compressive Sibson's } \\
\text { fascia, tight fascial band btwn } \\
\text { cervical rib \& middle scalene } \\
\text { muscle }\end{array}$ & 1 & 100 & None & 79 & Yes & $\begin{array}{l}\text { Pneumothorax ob- } \\
\text { served at OSH } \\
\text { on POD } 4\end{array}$ \\
\hline 4 & 28 & $\begin{array}{l}\text { Fibrous bands in the anterior } \\
\text { scalene muscle, Sibson's fascia } \\
\text { compressing lower trunk }\end{array}$ & 1 & 80 & $\begin{array}{l}\text { Occasional } \\
\text { w/ heavy } \\
\text { activity }\end{array}$ & 65 & Yes & $\begin{array}{l}\text { Fall down stairs on } \\
\text { POD } 2\end{array}$ \\
\hline 5 & 29 & $\begin{array}{l}\text { Fibrous bands in middle scalene } \\
\text { muscle, compressive Sibson's } \\
\text { fascia }\end{array}$ & 2 & 80 & None & 68 & Yes & None \\
\hline 6 & 42 & $\begin{array}{l}\text { Fibrous bands in the anterior sca- } \\
\text { lene muscle }\end{array}$ & 2 & 100 & $\begin{array}{r}\text { Occasional, } \\
\text { improved }\end{array}$ & 79 & Yes & None \\
\hline 7 & 50 & $\begin{array}{l}\text { Inferior portion of anterior scalene } \\
\text { muscle scarred \& adherent to } \\
\text { lower trunks, remnant of } 1 \text { st rib }\end{array}$ & 1 & 80 & $\begin{array}{r}\text { Occasional, } \\
\text { improved }\end{array}$ & 70 & Yes & None \\
\hline 8 & 1 & $\begin{array}{l}\text { Displacement of brachial plexus by } \\
\text { aberrant first thoracic rib }\end{array}$ & 2 & 100 & None & NA & NA & None \\
\hline 9 & 1 & $\begin{array}{l}\text { Displacement of brachial plexus by } \\
\text { cervical rib }\end{array}$ & 2 & 100 & None & NA & NA & None \\
\hline 10 & 10 & $\begin{array}{l}\text { Fibrous bands in the anterior sca- } \\
\text { lene muscle, compression of the } \\
\text { middle \& lower trunk }\end{array}$ & 1 & 90 & None & 78 & Yes & None \\
\hline 11 & 5 & $\begin{array}{l}\text { Hypertrophic anterior scalene } \\
\text { muscle w/ fibrous bands, com- } \\
\text { pression of lower \& upper trunk } \\
\text { by vascular structures }\end{array}$ & 1 & 100 & None & 77 & Yes & None \\
\hline 12 & 5 & $\begin{array}{l}\text { Elongated C-7 TP; fibrous band } \\
\text { deep to the lower \& middle trunks } \\
\text { \& extending from the TP to 1st rib } \\
\text { involving the medial border of the } \\
\text { middle scalene muscle, distorting } \\
\text { the plexus }\end{array}$ & 1 & 50 & $\begin{array}{r}\text { Occasional, } \\
\text { improved }\end{array}$ & 44 & Yes & None \\
\hline Mean \pm SD & $22.17 \pm 18.29$ & & & $88.14 \pm 15.08$ & & $74.36 \pm 9.94$ & & \\
\hline
\end{tabular}

FU = follow-up; LOS = length of hospital stay; NA = not available; $\mathrm{OSH}=$ outside hospital; $\mathrm{POD}=$ postoperative day; Rec = recommended.

* Case 1 and 3 patients underwent staged, bilateral procedures. 
middle scalenectomy in 1 case (7.14\%). The most common observations intraoperatively included the presence of fibrous bands within the anterior scalene in 11 cases (78.6\%); hypertrophied scalene muscles in 3 cases (21.4\%); and frank distortion of the brachial plexus by adjacent soft tissue, vascular, or bony structures in 5 cases $(35.7 \%)$. The patient with prior transaxillary first rib resection underwent external neurolysis of plexus elements with resection of the scar tissue that was thought to be related to his pain.

All patients were discharged to home following surgery, with approximately two-thirds of patients leaving on POD 1. There were 4 minor complications in 3 patients $(21.4 \%$ of cases) within 30 days of surgery. One patient suffered a transient increase in pain following surgery requiring a consultation visit by the pain management service, and then developed hiccups for a period of 3 hours that spontaneously resolved; 1 patient was diagnosed with a small pneumothorax on POD 4 at another hospital and was conservatively managed; 1 patient fell at home on POD 2, with resulting increased pain in her surgically treated arm, which had resolved at long-term follow-up.

The mean follow-up duration for all patients was 22.17 \pm 18.29 months, with a range of $1-59$ months). Clinical and long-term telephone follow-up was available for 12 cases; clinical follow-up alone was available in 2 cases. At the last postsurgical follow-up, complete resolution of pain was reported in 6 cases $(42.9 \%),>90 \%$ reduction in pain was reported in 2 cases $(14.3 \%),>50 \%$ reduction in pain was reported in 5 cases $(35.7 \%)$, and $50 \%$ reduction in pain was reported in 1 case $(7.14 \%)$. The mean reduction in pain was $88.14 \% \pm 15.08 \%$. Tingling and numbness resolved in 7 cases (50\%), decreased in 5 cases (35.7\%), and was only present with heavy activity in 2 cases $(14.3 \%)$. No patients reported worsening weakness following surgery.

Twelve cases were assessed using the UEFI at long-term telephone follow-up (Table 3). In 8 (72.7\%) of these cases, patients scored 71 points or higher, which is equivalent to normal function. Four patients had clinically detectable decreased scores in the UEFI ( $<71$ points); however, 1 of these patients described worsened function after a fall at home on POD 2 following a period of initial improvement, and 3 of these patients had a history of injuries or surgery to the affected shoulder and arm, and denied that their upper-extremity function had changed noticeably postoperatively. All patients surveyed responded "yes" to the question of whether they would recommend surgery for other patients with nTOS.

\section{Univariate Analysis}

Univariate analysis was undertaken to identify predictors of an excellent outcome, defined as a pain reduction of $\geq 90 \%$ ( 8 cases). With respect to continuous variables, patients who obtained $\geq 90 \%$ pain relief were significantly younger than patients who did not, with a mean age of 14 \pm 2.91 years versus $16.8 \pm 1.17$ years $(p=0.04)$. In addition, there was a trend toward a shorter duration of preoperative symptoms in the excellent outcomes group $(\mathrm{p}=0.08)$ compared with the good outcomes group. With respect to categorical variables, absence of a prior injury or trauma to the affected arm (such as a sports injury, fracture, or prior surgery) was significantly associated with an excel- lent outcome $(\mathrm{p}=0.05)$. The presence of an abnormal rib, cervical or thoracic, showed a trend toward predicting excellent outcomes $(p=0.13)$, but neither this nor a history of sports participation were significantly associated with excellent outcomes (Table 4).

\section{Discussion}

Thoracic outlet syndrome is an uncommon clinical syndrome of pain and functional impairment resulting from compression of vascular and/or nervous structures, most often between the anterior and middle scalene muscles and the first rib. Neurogenic TOS, which often presents without clear examination, imaging, or electrophysiological findings, can be a diagnosis of exclusion. Thus, nTOS is difficult to study systematically, because no consensus diagnostic criteria exist, and the symptoms of nTOS frequently overlap with other diagnoses. Whereas nTOS in adults accounts for $95 \%$ of all TOS diagnoses, nTOS is only observed in $26 \%$ of pediatric TOS cases, ${ }^{2,18}$ resulting in an even smaller pool of data. The total number of reported pediatric nTOS cases in the literature to date is fewer than 100 (Table 5). ${ }^{2-5,11-13,16,20,21,25,26,28-30}$ Further complicating our understanding of nTOS in children is the unfamiliarity of many pediatricians with this clinical entity, the difficulty of younger children in trying to communicate neurological symptoms, the reluctance to pursue aggressive or invasive testing in children, and the uncertain natural history of nTOS in a population that undergoes rapid growth and dramatic hormonal changes.

We undertook a 6-year retrospective review of outcomes in children with nTOS following surgical decompression to assess the role for surgery and to identify predictors for excellent outcomes following surgery. Because standardized long-term outcomes are underreported in this patient population, we obtained long-term follow-up data on our patients by using a patient-reported functional

TABLE 4. Univariate analysis of factors associated with $\geq$ $90 \%$ pain resolution following supraclavicular brachial plexus exploration and decompression

\begin{tabular}{lccc}
\hline \multicolumn{1}{c}{ Variable } & $\begin{array}{c}\text { Excellent } \\
\text { Outcome, } \\
\mathrm{n}=8\end{array}$ & $\begin{array}{c}\text { Good } \\
\text { Outcome, } \\
\mathrm{n}=6\end{array}$ & $\mathrm{p}$ Value \\
\hline & & & $\begin{array}{c}\text { Student t-test, } \\
\text { 2-tailed }\end{array}$ \\
\hline Age in yrs, mean $\pm \mathrm{SD}$ & $14 \pm 2.9$ & $16.8 \pm 1.2$ & $0.04^{*}$ \\
\hline $\begin{array}{c}\text { Duration of symptoms } \\
\text { prior to surgery in mos, } \\
\text { mean } \pm \text { SD }\end{array}$ & $13.1 \pm 6.44$ & $19.3 \pm 5.2$ & 0.08 \\
\hline
\end{tabular}

\begin{tabular}{llll}
\hline & & & $\begin{array}{c}\text { Fisher exact } \\
\text { test, 2-tailed }\end{array}$ \\
\hline Sports history & $7(87.5)$ & $5(83.3)$ & 0.52 \\
\hline Presence of abnormal rib & $5(62.5)$ & $1(16.7)$ & 0.13 \\
\hline $\begin{array}{l}\text { No previous surgery or } \\
\text { trauma }\end{array}$ & $8(100)$ & $3(50)$ & $0.05^{\star}$ \\
\hline
\end{tabular}

Unless otherwise indicated, values are expressed as the number of cases (\%). * Statistically significant. 
TABLE 5. Literature review of outcomes following surgical intervention for pediatric nTOS

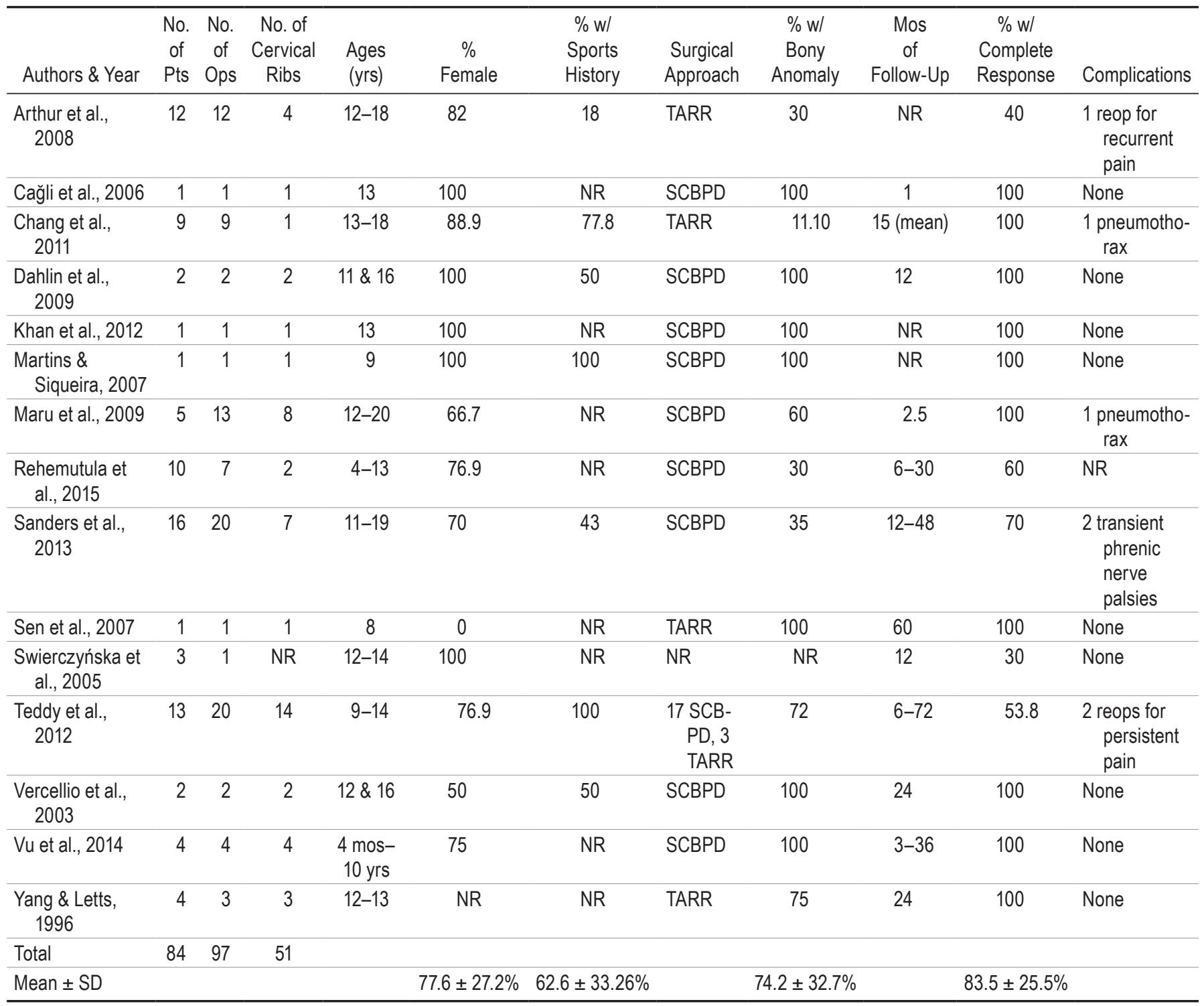

$\mathrm{NR}=$ not reported; Pts = patients; SCBPD = supraclavicular brachial plexus decompression, anterior scalenectomy, and resection of cervical rib when present.

index. We also attempted to better define the presenting characteristics and assess the utility of various diagnostic tests to assess for nTOS.

\section{Pediatric nTOS is a Challenging Diagnosis}

In our series, the average time to surgery from the onset of nTOS symptoms was $>1$ year (15.8 \pm 6.6 months $)$, which is consistent with other series. ${ }^{4,16,26}$ This is partially due to the trial of physical therapy that our patients undergo prior to surgery, but it also reflects a delay in diagnosis due to extensive work-ups, consideration of other conditions, or failed pain management. A delay in surgical evaluation and management is understandable because initial imaging of the cervical spine and brachial plexus is frequently negative (approximately 75\% in our series), and other diagnoses may be pursued in the absence of evidence for injury or compression. The rate of negative MRI findings is also high in other similarly sized case series, ${ }^{2,26}$ and Sanders et al. state that they found MRI to be expensive and unhelpful, and that they no longer routinely order the test. ${ }^{20}$ In our experience, US of the brachial plexus with dynamic maneuvers was more helpful in demonstrating compression of nervous and vascular structures $(50 \%$ of cases), which might suggest an underlying mechanism for injury. With regard to the diagnostic utility and predictive power of a response to a US-guided steroid injection, our results were mixed ( 1 patient responded to injection and had an excellent outcome of surgery, 2 patients responded and had good outcomes, and 1 patient did not respond and had an excellent outcome).

Electrophysiological studies (i.e., EMG and NCS) were generally unhelpful in diagnosing nTOS in our cohort. This has also been observed in other series, where rates 
of abnormal EMG and NCS findings range from 7.69\% to $11 \%$ in children with nTOS. . $^{2-11-13,16,20,21,25,26,28-30}$ The reliability of provocative maneuvers is notoriously low, and our patients demonstrated a 71.4\% likelihood of a positive Roos sign, a $64.3 \%$ likelihood of a positive Tinel's sign, and a $51.7 \%$ likelihood of tenderness to palpation over the brachial plexus. Although the majority of our patients exhibited 1 of these 3 findings on examination (12/14 cases, $85.7 \%$ ), the presence of a positive provocative maneuver was not associated with a good surgical outcome. We did not report the percentage of positive findings with Adson's maneuvers because the Adson's test has been noted to be positive in $50 \%$ of the normal population. ${ }^{2}$

The most convincing evidence for nTOS in our experience is a combination of a clinical history of persistent debilitating pain, accompanied by numbness or paresthesias that are exacerbated by overhead arm movements, with a significant sports history and a plain cervical radiograph demonstrating a bony anomaly. These 4 factors were observed in 8 cases $(57.1 \%)$, and 2 of these 4 factors were observed in all cases.

\section{Surgical Treatment is Effective and Safe for Pediatric nTOS}

In our cohort, $57.1 \%$ of our cases (8 patients) reported $>90 \%$ reduction in pain at a mean follow-up period of 22 months after surgical decompression of the thoracic outlet. If patients who reported $>50 \%$ pain relief are also considered responders to surgery, the success rate of surgical decompression in our series increases to $92 \%$. This high rate of durable pain relief is consistent with what has previously been observed in case series with $>5$ cases of pediatric nTOS (mean complete response rate of 63.3\%). ${ }^{2,4,13}$, ${ }^{16,20}$ Furthermore, there were no major 30-day complications in our patients. In the literature, the most commonly observed complications are transient phrenic nerve injuries $(2 \%)$ and pneumothoraces (2\%). Whereas a 3\% reoperation rate was seen in previous studies (Table 5), no patients required reoperation in our group for reexploration of the brachial plexus during the follow-up period. However, it is possible that patients with short-term follow-up may have yet to present with recurrent symptoms, because the average time to recurrence was 18 months in a large adult series. ${ }^{1}$ Two patients did elect to undergo subsequent orthopedic shoulder operations on the same side as their nTOS. Although both of these patients failed to obtain > 90\% pain relief after nTOS surgery, they did recommend the surgery to other patients at long-term follow-up. This highlights the challenge of treating nTOS symptoms, which rarely respond to conservative management. Even partial pain relief with surgery results in high patient satisfaction, although frank counseling about the anticipated outcomes and risks of surgery is essential.

The role and extent of bone resection in surgical treatment for nTOS is debated. One series reported that more complications were associated with bone resection, ${ }^{26}$ leading some surgeons to advocate for soft-tissue resection alone, even in cases with cervical ribs. ${ }^{17}$ We prefer the supraclavicular approach in part because it provides excellent outcomes in many patients without bone removal; however, if the brachial plexus is deviated by bone after anterior scalenectomy, bone removal may be required to adequately decompress the neural elements. We do not recommend routine removal of any abnormal bony element. For example, enlarged C-7 TPs are not resected unless they contact the brachial plexus.

Of the patients who did not attain excellent pain relief following surgery, the reasons for failure are unclear. Some groups have invoked the double-crush hypothesis to explain persistent symptoms, ${ }^{20}$ suggesting that a brachial plexus exploration alone may not address other superimposed sites of entrapment. However, only 1 of our unresponsive patients had an abnormal result on EMG that was consistent with C-5 radiculopathy. No other EMG or examination findings demonstrated additional sites of entrapment in the 5 other cases with residual pain after surgery. More likely, diagnostic uncertainty in combination with potential reinjury ( 1 of our patients fell on her surgically treated extremity shortly after discharge from the hospital, and 2 other patients had additional orthopedic shoulder surgeries) is at fault. In our experience, patients with $<90 \%$ pain relief after surgery at long-term follow-up were significantly more likely to have a history of trauma or prior surgery to the affected limb, which could result in complex, painful injuries to neighboring structures or the development of chronic pain syndromes in addition to damage to the brachial plexus. Based on this group, we now counsel pediatric patients with nTOS who have had prior trauma or surgery that brachial plexus decompression alone is less likely to result in an excellent outcome. It is also possible that some patients had compression or irritation of the plexus elements outside of the interscalene triangle. We did not routinely explore the infraclavicular plexus, because this is an extremely rare site of TOS. We have not pursued additional evaluation for these patients because they report very high satisfaction with surgery, despite less than excellent pain outcomes.

Careful selection of patients who will most likely benefit from surgery is critical. In our analysis of factors associated with complete resolution of pain after surgery, the presence of abnormal ribs on imaging trended toward statistical significance, an association that may have been more apparent with larger numbers of patients. This suggests that an anatomical predisposition to entrapment is a risk for development of pediatric nTOS, and surgical decompression has a greater likelihood of success when patients have static compression in addition to dynamic compression.

Unfortunately, there is an absence of good observational data about long-term results of conservative management as compared with surgery. Only 2 papers report positive outcomes for children who underwent conservative management. Rehemutula et al. described 3 children (ages 6 , 6 , and 7 years) who presented with nTOS and underwent intensive physical therapy and posture correction with local analgesic blocks of the anterior and middle scalene. At a minimum of 6 months of follow-up, these children were described as having satisfactory outcomes. ${ }^{16}$ Yang and Letts elected to observe 2 children with nTOS, ages 12 and 13 years, who did not have cervical ribs on imaging. Over a period of 2 years, they reported that the pain symptoms resolved with avoidance of the inciting arm po- 
sitions. ${ }^{30}$ In each case, the children whose nTOS was managed successfully with conservative measures were earlier-presenting patients with relatively mild symptoms. In light of these findings, we recommend a trial of conservative management in all patients prior to consideration for surgery. A few of our patients undergo US-guided steroid injections of the brachial plexus, in addition to noninvasive physical therapy. Ultimately the patients who elect to undergo brachial plexus decompression surgery are those in whom physical therapy or other pain management techniques fail, and they or a parent or guardian understand and consent to the risks of surgery.

\section{Early Surgery May Result in Better Outcomes}

Univariate analyses of factors that might be associated with an excellent surgical outcome, defined as pain relief of $\geq 90 \%$, determined that patients who had excellent outcomes were significantly younger than those who did not. In addition, patients with excellent outcomes trended toward having shorter durations of preoperative symptoms. These 2 factors may be covariant, because patients who present for surgical assessment earlier in the course of their disease are likely to be younger. Taken together, these 2 factors suggest that expediting surgical evaluation may result in better long-term outcomes, perhaps because it decreases the duration of brachial plexus compression and forestalls the development of a chronic pain syndrome. Another possibility is that older children may have less neural plasticity and intrinsic regenerative abilities, in addition to a more severe or long-standing underlying neurological injury.

\section{Pediatric Versus Adult nTOS: Different Mechanisms of Injury?}

Neurogenic TOS is much less common in the pediatric population compared with adults; however, the incidence of cervical ribs in the pediatric nTOS population is much higher. In our cohort, $64.5 \%$ of nTOS cases were associated with a bony anomaly. This agrees with previous studies that demonstrate the rate of cervical ribs in the pediatric nTOS population to be approximately $53 \%$ (Table 5). In contrast, the incidence of cervical ribs in a recently published adult TOS series with 538 patients was 8.8\%.15 This discrepancy suggests that the mechanisms of injury in adult nTOS and pediatric nTOS are divergent and may be more anatomical than functional in children. There may also be a mechanism by which nTOS can resolve spontaneously in adulthood after a period of growth or development in children with cervical ribs. Currently, we do not understand the natural history of pediatric nTOS sufficiently to predict how symptoms may change over long periods of time.

Adults with nTOS often report a history of trauma. ${ }^{6}$ In comparison, trauma was relatively rare in our pediatric cases (3 patients). However, nearly all of our patients played sports, many with an overhead motion component. A significant sports history was also noted in several other larger pediatric nTOS case series. ${ }^{4,26,28}$ This suggests that in adults, formation of scar tissue and direct injury to nervous structures may incite the development of nTOS, but in children, the underlying mechanical forces may relate more to hypertrophy of muscles (particularly in a crowded region of the neck, and in the context of a cervical rib) and direct compression or entrapment of the plexus. Another hypothesis is that both kinds of injury result in a chronic inflammatory state that is uniquely detrimental to nerve tissue. Rehemutula et al. sent 4 lymph node biopsies for pathological analysis from the fat pad of the posterior cervical triangle, which appeared large; all 4 were found to have chronic inflammation. ${ }^{16}$ We do not routinely perform lymph node biopsies, but the 3 children who responded to US-guided steroid injections of the plexus in our series may offer evidence that antiinflammatory strategies are useful adjuncts to surgery. No studies have examined the utility of brachial plexus injections in nTOS, as either a diagnostic or therapeutic tool for children. Two studies describe anterior scalene muscle blocks to be predictive of successful surgical outcomes in nTOS in adults. ${ }^{1,10}$ We are currently studying the positive predictive value of these injections, but the lack of response is not a contraindication to surgery.

\section{Limitations of the Study}

The primary limitations of our study are its retrospective nature and nonblinded postoperative assessments. Patients are more likely to underreport negative outcomes when the questioner is their surgeon. To address these shortcomings, prospective, long-term observational trials with patient-reported quality of life measures need to be performed.

\section{Conclusions}

Pediatric nTOS is a rare pain syndrome that can be challenging to diagnose. Surgical decompression of the thoracic outlet results in complete pain relief in approximately one-half to two-thirds of patients, and $>50 \%$ pain relief in $90 \%$ of patients. Complications are rare but potentially serious, such as phrenic nerve injury and pneumothorax. Adult and pediatric nTOS may differ in pathogenesis and response to treatment.

\section{References}

1. Ambrad-Chalela E, Thomas GI, Johansen KH: Recurrent neurogenic thoracic outlet syndrome. Am J Surg 187:505510,2004

2. Arthur LG, Teich S, Hogan M, Caniano DA, Smead W: Pediatric thoracic outlet syndrome: a disorder with serious vascular complications. J Pediatr Surg 43:1089-1094, 2008

3. Cağli K, Ozçakar L, Beyazit M, Sirmali M: Thoracic outlet syndrome in an adolescent with bilateral bifid ribs. Clin Anat 19:558-560, 2006

4. Chang K, Graf E, Davis K, Demos J, Roethle T, Freischlag JA: Spectrum of thoracic outlet syndrome presentation in adolescents. Arch Surg 146:1383-1387, 2011

5. Dahlin LB, Backman C, Düppe H, Saito H, Chemnitz A, Abul-Kasim K, et al: Compression of the lower trunk of the brachial plexus by a cervical rib in two adolescent girls: case reports and surgical treatment. J Brachial Plex Peripher Nerve Inj 4:14, 2009

6. Fugate MW, Rotellini-Coltvet L, Freischlag JA: Current management of thoracic outlet syndrome. Curr Treat Options Cardiovasc Med 11:176-183, 2009

7. Hefford C, Abbott JH, Arnold R, Baxter GD: The patient- 
specific functional scale: validity, reliability, and responsiveness in patients with upper extremity musculoskeletal problems. J Orthop Sports Phys Ther 42:56-65, 2012

8. Hempel GK, Shutze WP, Anderson JF, Bukhari HI: 770 consecutive supraclavicular first rib resections for thoracic outlet syndrome. Ann Vasc Surg 10:456-463, 1996

9. Huang JH, Zager EL: Thoracic outlet syndrome. Neurosurgery 55:897-903, 2004

10. Jordan SE, Machleder HI: Diagnosis of thoracic outlet syndrome using electrophysiologically guided anterior scalene blocks. Ann Vasc Surg 12:260-264, 1998

11. Khan A, Rattihalli RR, Hussain N, Sridhar A: Bilateral thoracic outlet syndrome: An uncommon presentation of a rare condition in children. Ann Indian Acad Neurol 15:323-325, 2012

12. Martins RS, Siqueira MG: Cervical rib fracture: an unusual etiology of thoracic outlet syndrome in a child. Pediatr Neurosurg 43:293-296, 2007

13. Maru S, Dosluoglu H, Dryjski M, Cherr G, Curl GR, Harris LM: Thoracic outlet syndrome in children and young adults. Eur J Vasc Endovasc Surg 38:560-564, 2009

14. O'Brien PJ, Ramasunder S, Cox MW: Venous thoracic outlet syndrome secondary to first rib osteochondroma in a pediatric patient. J Vasc Surg 53:811-813, 2011

15. Orlando MS, Likes KC, Mirza S, Cao Y, Cohen A, Lum YW, et al: A decade of excellent outcomes after surgical intervention in 538 patients with thoracic outlet syndrome. J Am Coll Surg 220:934-939, 2015

16. Rehemutula A, Zhang L, Chen L, Chen D, Gu Y: Managing pediatric thoracic outlet syndrome. Ital J Pediatr 41:22, 2015

17. Rochkind S, Shemesh M, Patish H, Graif M, Segev Y, Salame K, et al: Thoracic outlet syndrome: a multidisciplinary problem with a perspective for microsurgical management without rib resection. Acta Neurochir Suppl 100:145-147, 2007

18. Roos D: Overview of thoracic outlet syndromes, in Machleder HI (ed): Vascular Disorders of the Upper Extremity. Mount Kisco, NY: Futura, 1989, pp 155-177

19. Sanders RJ: Results of the surgical treatment for thoracic outlet syndrome. Semin Thorac Cardiovasc Surg 8:221-228, 1996

20. Sanders RJ, Annest SJ, Goldson E: Neurogenic thoracic outlet and pectoralis minor syndromes in children. Vasc Endovascular Surg 47:335-341, 2013

21. Sen S, Dişçigil B, Boga M, Ozkisacik E, Inci I: Thoracic outlet syndrome with right subclavian artery dilatation in a child - transaxillary resection of the pediatric cervical rib. Thorac Cardiovasc Surg 55:339-341, 2007
22. Shepherd J: Thoracic outlet compression syndrome: a rare cause of upper extremity symptoms in children. J Am Board Fam Pract 12:403-405, 1999

23. Stansby G, Lambert D: Thoracic outlet syndrome in children and young adults. Eur J Vasc Endovasc Surg 38:565-566, 2009

24. Stratford PW, Binkley JM, Stratford DM: Development and initial validation of the upper extremity functional index. Physiother Can 53:259-267, 2001

25. Swierczyńska A, Kłusek R, Kroczka S: [Neurorehabilitation in children with thoracic outlet syndrome and its assessment.] Przegl Lek 62:1308-1313, 2005 (Polish)

26. Teddy PJ, Johnson RD, Cai RR, Wallace D: Surgery for paediatric thoracic outlet syndrome. J Clin Neurosci 19:235240, 2012

27. Turgut M: Thoracic outlet syndrome in children. J Pediatr Orthop 17:697, 1997

28. Vercellio G, Baraldini V, Gatti C, Coletti M, Cipolat L: Thoracic outlet syndrome in paediatrics: clinical presentation, surgical treatment, and outcome in a series of eight children. J Pediatr Surg 38:58-61, 2003

29. Vu AT, Patel PA, Elhadi H, Schwentker AR, Yakuboff KP: Thoracic outlet syndrome in the pediatric population: case series. J Hand Surg Am 39:484-487, 487.e1-487.e2, 2014

30. Yang J, Letts M: Thoracic outlet syndrome in children. J Pediatr Orthop 16:514-517, 1996

\section{Disclosures}

The authors report no conflict of interest concerning the materials or methods used in this study or the findings specified in this paper.

\section{Author Contributions}

Conception and design: Hong, Ali, GG Heuer. Acquisition of data: Zager, Hong, Pisapia, Alexander, AJ Heuer. Analysis and interpretation of data: Hong, Ali, GG Heuer. Drafting the article: Hong, Pisapia. Critically revising the article: all authors. Reviewed submitted version of manuscript: all authors. Statistical analysis: Hong. Study supervision: Hong.

\section{Correspondence}

Eric L. Zager, Department of Neurosurgery, University of Pennsylvania, 3400 Spruce St., 3rd Fl. Silverstein Pavilion, Philadelphia, PA 19104.email: eric.zager@uphs.upenn.edu. 